\title{
Relationship between absence of lactobacilli in the vagina of pregnant women and preterm birth: A retrospective pilot study
}

\author{
Drew RJ ${ }^{1-3 *}$, LeBlanc $\mathrm{L}^{4}$, Kent $\mathrm{E}^{5}$ and Eogan $\mathrm{M}^{5}$ \\ ${ }^{1}$ Clinical Innovation Unit, Rotunda Hospital, Ireland \\ ${ }^{2}$ Irish Meningitis and Sepsis Reference Laboratory, Temple Street Hospital, Ireland \\ ${ }^{3}$ Department of Microbiology, Royal College of Surgeons in Ireland, Ireland \\ ${ }^{4}$ Medical Student, Royal College of Surgeons in Ireland, Ireland \\ ${ }^{5}$ Department of Obstetrics, Rotunda Hospital, Ireland
}

\begin{abstract}
Abnormal depletion of lactobacilli, particularly during the second trimester, has been associated with preterm birth. The aim of this retrospective single-centre casecontrol study was to compare patient characteristics and pregnancy related outcomes for women depending on the Gram stain results of their high vaginal swab. Cases were pregnant women with an absence of lactobacilli seen yet did not have the features of Bacterial Vaginosis (BV) such as predominance of Gardnerella vaginalis and other bacterial morphotypes associated with BV. These cases were suggestive of having aerobic vaginitis and designated as grade IV in line with modified Hay's criteria. Controls were pregnant women with a Grade I (predominantly lactobacilli) as per the Hay's criteria.

Nineteen cases were identified during the four-month study period in the single centre maternity hospital where the study was performed. Thirty-eight consecutive controls (1:2 ratio) were chosen as comparators. Cases had a statistically significant higher rate of preterm delivery, preterm premature rupture of the membranes, shorter interval between swab sampling and delivery, and also longer admission of the mother at the time of delivery (all p<0.05). Cases also showed a trend towards lower rates of nulliparity, lower rate of survival of the baby and longer duration of the baby in Neonatal Intensive Care Unit ( $p$ values between 0.05 and 0.1 ). In terms of microbiological culture results, cases had a higher colonisation with $E$. coli, while controls had a higher rate of Candida growth.

This study has highlighted the link between an absence of lactobacilli, higher rate of $E$. coli colonisation and preterm birth with adverse neonatal outcomes. Future work should determine if it is possible to identify pregnant women in the second trimester with a loss of lactobacilli, who could potentially benefit from further screening and targeted interventions eg supplementation with lactobacilli containing probiotics.
\end{abstract}

\section{Introduction}

During pregnancy, the vagina of women becomes dominated with lactobacilli, and this leads to a very acidic environment which reduces the risk of invasion by aerobic pathogens such as group B Streptocccus and E. coli [1,2], which are leading causes of both maternal and early onset neonatal bacteraemia. This significant decrease in vaginal microbial richness and diversity has been shown in African-American population to occur early in pregnancy at the start of the second trimester [3]. In this way preterm birth may be related to loss of lactobacilli, with an associated greater risk of mortality and morbidity in the neonate due to complications of prematurity [4].

The lactobacillus dominated environment is very stable and has been associated with a lower risk of preterm birth in comparison to lactobacilli depleted women. Women with Preterm Premature Rupture of the Membranes (PPROM) have been shown to have an absence of lactobacilli at the time of rupture, and this can persist until delivery [5] but they may have vaginal infection in this case, which can reduce the lactobacilli colonisation. This result could be related to the increase risk of PPROM in setting of vaginal infection. A clinical problem with many of these studies is that they use $16 \mathrm{~s}$ rDNA technology that is not widely available, nor economically viable for routine clinical use and consequent patient triage [6]. Molecular based testing will be an option; however, this is still at the research development stage. By using traditional Gram staining to classify women, it is possible to use the
Hay's criteria to determine if the presence of lactobacilli is normal or reduced, and this creates the possibility of developing tests for routine clinical use. For patients with reduced presence of lactobacilli, this could be related to bacterial vaginosis if there are other morphotypes or if Gardnerella vaginalis is present. However, if lactobacilli are absent, and there is no sign of bacterial vaginosis, then this may represent aerobic vaginitis, although this would have to be correlated with clinical symptoms and signs [7-9].

The objective of this study was to compare patient characteristics and pregnancy related outcomes between pregnant women with a lactobacillus dominated vagina (controls Grade I), and those with loss of lactobacilli but no evidence of bacterial vaginosis who may have aerobic vaginitis (cases grade IV). Our hypothesis is that pregnant women, with an absence of lactobacilli, are more likely to have preterm rupture of the membranes and preterm birth.

*Correspondence to: Drew RJ, Consultant Microbiologist, Rotunda Hospital, Ireland, Tel: +353-1-8171700; E-mail: rdrew@rotunda.ie

Key words: lactobacillus, lactobacilli, aerobic vaginitis, Preterm birth, vaginal microbiome

Received: August 03, 2018; Accepted: August 24, 2018; Published: August 29, 2018 


\section{Materials and methods}

This was a retrospective audit and approved by the Ethics Committee of the Rotunda Hospital (RAAG-2018-013). The study was carried out at the Rotunda Hospital, a stand-alone large tertiary maternity hospital with approximately 9000 births per year. Women were identified for the study through the laboratory information system of the hospital, and clinical details were recorded from the electronic health record system.

All Gram stains performed on high vaginal swabs between January and April 2018 were identified. These swabs were sent to the laboratory as part of routine investigation (eg investigation of abnormal genital tract symptoms or in the context of a septic screen) and no additional swabs were taken solely for the purposes of this study. Routine screening for group B streptococcus was not in place in our hospital, and the risk factor-based approach was used as recommended by the Royal College of Obstetricians and Gynaecologists. The risk factors identified in this guideline are having a previous baby with GBS disease, maternal GBS carriage, preterm birth, prolonged rupture of membranes, suspected intrapartum maternal fever and infection. Gram stains were performed for the assessment of bacterial vaginosis using the Hay's criteria. Grades I, II and III were reported as per the Standard Hay's criteria
[10] (Table 1). However, for samples with few or absent lactobacilli, that did not have increased numbers of Gardnerella vaginalis or other bacterial morphotypes, these were included as Grade IV. This group could constitute samples which may reflect aerobic vaginitis, although a full Nugent' criteria assessment was not performed. Patients with a grade IV result were included in the analysis as cases, while patients with grade I results were included as controls. For this pilot study 1:2 ratio of cases to controls was used to determine if there are any relevant risk factors for this abnormal Gram stain result. Cases represented a retrospective consecutive series and controls were also selected in a consecutive sequence over the duration of the study.

Laboratory results and patient details were then transferred using a study code onto an Excel spreadsheet. For categorical variables, the chi-square test was used or if a parameter was less than five then the Fisher exact test was used. For continuous variables, as they did not have a normal Gaussian distribution, they were analysed using the Mann-Whitney U test (Graph-Pad Prism, version 5, United States of America). The survival curve was drawn using GraphPad Prism, and the scatter plot in figure 1 was drawn using the statistical software package R ( $\mathrm{R}$ Foundation for Statistical Computing, version 3.5.1, Austria).

Table 1. Modified Hay's criteria used in this study, based on Public Health England Standards for Microbiological Investigation of Genital Tract samples for bacterial vaginosis

\begin{tabular}{|l|l|l|l|}
\hline Grade & Abundance of Lactobacilli present & Overall Gram stain appearance & Included in this study \\
\hline Grade I & Normal & Predominantly lactobacillus morphotypes & Referred to as "controls" \\
\hline Grade II & Intermediate & Mixed Lactobacillus and other morphotypes. & Excluded from analysis \\
\hline Grade III & Abnormally low & $\begin{array}{l}\text { Few or absent Lactobacillus, but greatly increased number of Gardnerella } \\
\text { vaginalis and other bacterial morphotypes }\end{array}$ & Excluded from analysis \\
\hline Grade IV & Abnormally low & $\begin{array}{l}\text { Few or absent Lactobacillus, (Gardnerella vaginalis and other bacterial } \\
\text { morphotypes } \boldsymbol{N O T} \text { seen }\end{array}$ & Referred to as "cases" \\
\hline
\end{tabular}

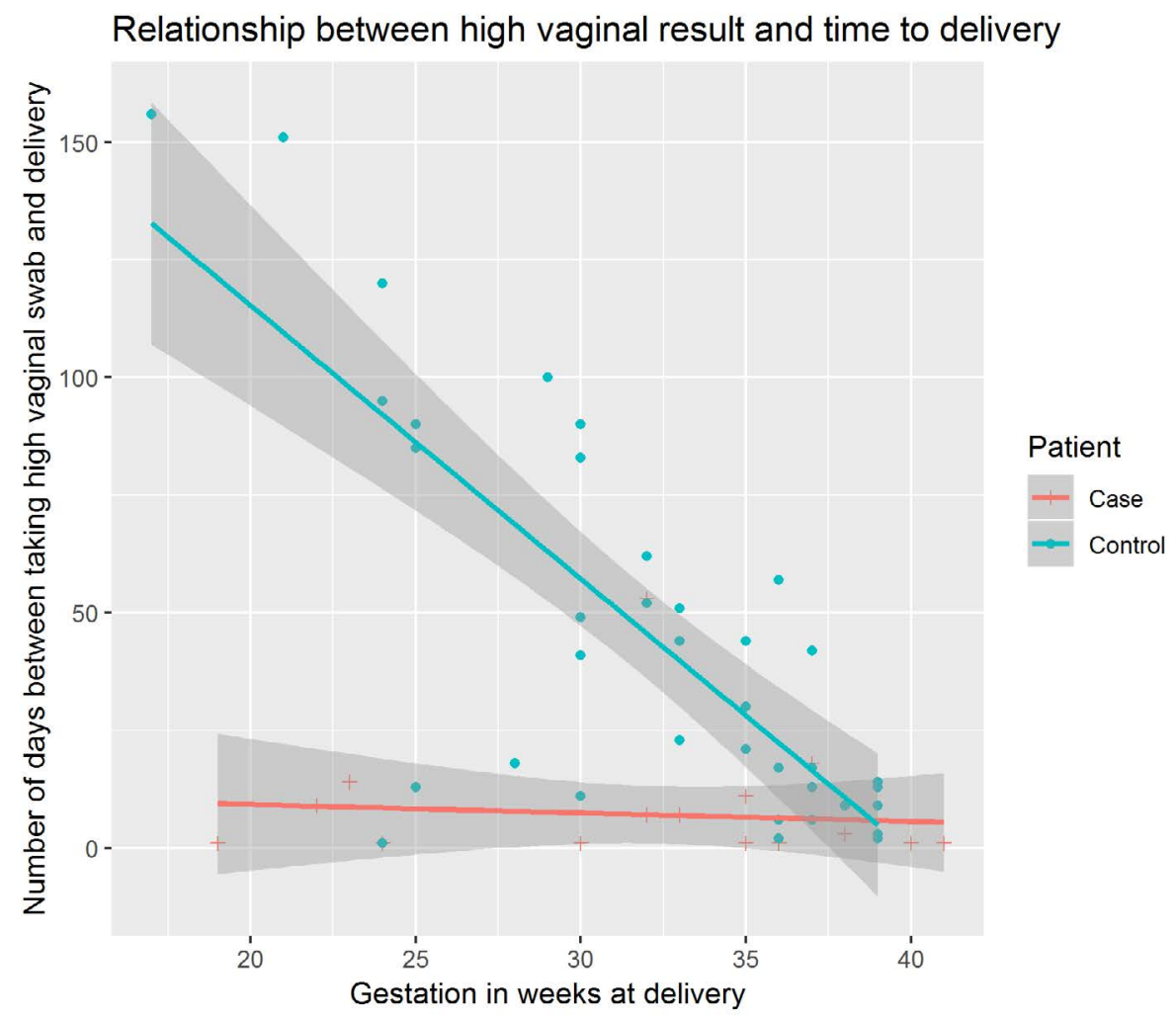

Figure 1. Relationship between presence of Lactobacilli on Gram stain of the high vaginal swab and the time to delivery 


\section{Results}

During the study period from January to April 2018, there were 1,410 high vaginal swab samples sent to the laboratory from 1,339 patients. One hundred and fifteen patients $(8.5 \%)$ were intermediate (Grade II), 79 (5\%) patients had a Gram stain consistent with Bacterial vaginosis (Grade III) and 76 patients (5\%) were identified in the grade 4 group. Fifty-seven of these were excluded as they were either postnatal at the time of sampling or were sent from gynaecology services, leaving 19 pregnant women with Grade IV Gram stain results included in the study ('cases'). A consecutive series of 38 pregnant women (1:2 ratio) were selected from the Grade I group to act as controls.

The overview of patient characteristics is shown in table 2 . There was no statistical difference seen with respect to maternal age, prevalence of multiple gestation and also maternal weight at the time of booking. The cases however had a statistically significant higher rate of preterm delivery, and also duration of admission for the mother. The trend towards statistical significance was present for the duration of admission of the baby and for nulliparity however it did not achieve statistical significance level of $\mathrm{p}<0.05$.

The most common indication for taking a swab in the case group was presenting with preterm premature rupture of the membranes, while in the control group the most common indication was the presence of a vaginal discharge (Table 3). In both groups normal flora was the predominant finding in bacterial culture, however there was an increased rate of candida detected in the control group. The prevalence of group B streptococcus was less than or equal to $10 \%$ in both groups, but $E$. coli was more prevalent in cases (7/19 [36\%] cases vs. 3/38 [8\%] controls, Fisher exact test $\mathrm{p}<0.01$ ).

When comparing the interval between the swab being performed and birth of the baby, there was a negative correlation for controls in line with the expectation that the earlier in pregnancy the swab was taken the longer it would be until delivery. However, for the cases there was no correlation between the gestation at delivery and the time between the swab being taken and delivery (Figure 1). Patients in the control group delivered at a later gestation in comparison to cases, and this difference was statistically significant $(\mathrm{p}<0.01)$ (Figure 2).

As the data was non-Gaussian in distribution, Mann-Whitney $U$ test was used for continuous variables. Chi-square test was used for categorical variables except if a factor was less than five, in which case the Fisher exact t-test was used.

\section{Discussion}

This retrospective study, although limited in terms of patient numbers, has shown that pregnant women who have a loss of lactobacilli, with no evidence of bacterial vaginosis, have a higher risk than controls of preterm labour and preterm premature rupture of membranes. These morbidities result in a longer duration of admission for the mother and baby. In line with our hypothesis this potentially identifies a physiological mechanism which can trigger preterm birth, although larger studies are needed. Of concern, there was a higher colonisation rate with $E$. coli in cases than controls, and this could be relevant for the development of chorioamnionitis and early onset $E$. coli sepsis. Controls had a higher rate of Candida colonisation, but this may reflect the fact that the most common indication for testing in controls was presence of abnormal vaginal discharge. This matches a finding from a large systematic review which showed that Candida colonisation was more common in women with lactobacilli dominated flora [11]. Although we did not examine the exact mechanism of how the absence of lactobacilli can trigger rupture of membranes, it may be related to abnormal bacterial overgrowth leading to low grade inflammation. The findings of this study could direct future research in to examining the pregnancy outcome of women with high vaginal swabs showing a depletion of lactobacilli.

A significant limitation to this study is that all these swabs were done for a clinical indication eg $63 \%$ of women had ruptured

Table 2. Patient characteristics and outcome measures ( $\mathrm{n} / \mathrm{s}=$ not statistically significant)

\begin{tabular}{|c|c|c|c|}
\hline Criteria & Cases (Grade IV) & Controls (Grade I) & Statistical comparison \\
\hline Number of participants & 19 & 38 & \\
\hline Age in years [median(range)] & $33(23-39)$ & $31(19-45)$ & $\mathrm{n} / \mathrm{s}$ \\
\hline Nulliparous [n, (\%)] & $5(26.3 \%)$ & $20(52 \%)$ & $\mathrm{p}=0.06$ \\
\hline Multiple gestation [n, (\%)] & $1(5.2 \%)$ & $2(5 \%)$ & $\mathrm{n} / \mathrm{s}$ \\
\hline $\begin{array}{l}\text { Maternal weight (kg) at time of booking } \\
\text { [median(range)] }\end{array}$ & $66 \mathrm{Kg}(50-119 \mathrm{Kg})$ & $70 \mathrm{Kg}(55-103 \mathrm{Kg})$ & $\mathrm{n} / \mathrm{s}$ \\
\hline $\begin{array}{l}\text { Gestation in weeks at time of swab } \\
\text { [Median, (range)] }\end{array}$ & $35(19-41)$ & $33(17-39)$ & $\mathrm{n} / \mathrm{s}$ \\
\hline Preterm delivery ( $<37 / 40$ weeks gestation) & $14(73.7 \%)$ & $5(13.2 \%)$ & $\mathrm{p}<0.0001$ \\
\hline $\begin{array}{l}\text { Number of days between taking of swab } \\
\text { and delivery of the baby [Median(range)] }\end{array}$ & $1(1-53)$ & $35(1-156)$ & $\mathrm{p}<0.0001$ \\
\hline Neonate alive at birth $[\mathrm{n},(\%)]$ & $\begin{array}{l}19 \text { of } 20 \text { babies }(95 \%) \text {. Note single } \\
\text { miscarriage at } 19 \text { weeks. One set of twins } \\
\text { in cohort }\end{array}$ & $\begin{array}{l}39 \text { of } 40 \text { babies }(97.5 \%) . \text { Note two sets of } \\
\text { twins in cohort }\end{array}$ & $\mathrm{n} / \mathrm{s}$ \\
\hline $\begin{array}{l}\text { Duration of admission of the mother in } \\
\text { days [Median, (range)] }\end{array}$ & $6(2-15)$ & $4(0-9)$ & $\mathrm{p}=0.01$ \\
\hline $\begin{array}{l}\text { Duration of admission of the baby in days } \\
\text { [Median, (range)] }\end{array}$ & $5(2-140)(n=19)$ & $4(1-34)(n=39)$ & $\mathrm{p}=0.08$ \\
\hline Neonate survived to discharge $[\mathrm{n},(\%)]$ & 16/19 (84\%). Miscarriage case excluded & $38 / 39(97 \%)$. Stillbirth case excluded. & $\mathrm{p}=0.09$ \\
\hline \multicolumn{4}{|l|}{ Mode of delivery } \\
\hline C-section & $9(47 \%)$ & $17(44.7 \%)$ & $\mathrm{n} / \mathrm{s}$ \\
\hline Spontaneous vaginal & $6(31.6 \%)$ & $15(39.4 \%)$ & $\mathrm{n} / \mathrm{s}$ \\
\hline Operative vaginal & $3(16 \%)$ & $6(15.7 \%)$ & $\mathrm{n} / \mathrm{s}$ \\
\hline Miscarriage & $1(5 \%)$ & $0(0 \%)$ & $\mathrm{n} / \mathrm{s}$ \\
\hline
\end{tabular}


Table 3. Indication for taking the high vaginal swab and the organisms cultured

\begin{tabular}{|l|l|l|}
\hline \multicolumn{2}{|l|}{ Cases (n=19) } & Controls (n=38) \\
\hline $\begin{array}{l}|l| \\
\text { Indication for swab being taken } \\
\text { membranes }\end{array}$ & $12(63 \%)$ & $1(2.6 \%)$ \\
\hline Vaginal discharge & $3(16 \%)$ & $30(78.9 \%)$ \\
\hline Pyrexia & $1(5 \%)$ & $2(5.2 \%)$ \\
\hline Chorioamnionitis & $1(5 \%)$ & $0(0 \%)$ \\
\hline Miscarriage & $1(5 \%)$ & $0(0 \%)$ \\
\hline Rupture of membranes $>18$ hours & $1(5 \%)$ & $0(0 \%)$ \\
\hline Itch & $0(0 \%)$ & $3(7.8 \%)$ \\
\hline Abdominal pain & $0(0 \%)$ & $1(2.6 \%)$ \\
\hline Preterm labour & $0(0 \%)$ & $1(2.6 \%)$ \\
\hline Organism cultured from high vaginal swab & \\
\hline Normal flora & $7(36.8 \%)$ & $19(50 \%)$ \\
\hline E.coli & $5(26 \%)$ & $3(7.8 \%)$ \\
\hline E.coli and Candida spp. & $2(10 \%)$ & $0(0 \%)$ \\
\hline Candida spp. & $2(10 \%)$ & $11(28.9 \%)$ \\
\hline Group B Streptococcus & $2(10 \%)$ & $3(7.8 \%)$ \\
\hline Enterococcus faecalis & $1(5 \%)$ & $0(0 \%)$ \\
\hline Proteus spp & $0(0 \%)$ & $1(2.6 \%)$ \\
\hline Group B Streptococcus and Candida spp. & $0(0 \%)$ & $1(2.6 \%)$ \\
\hline & &
\end{tabular}

Gestation at delivery by high vaginal swab result

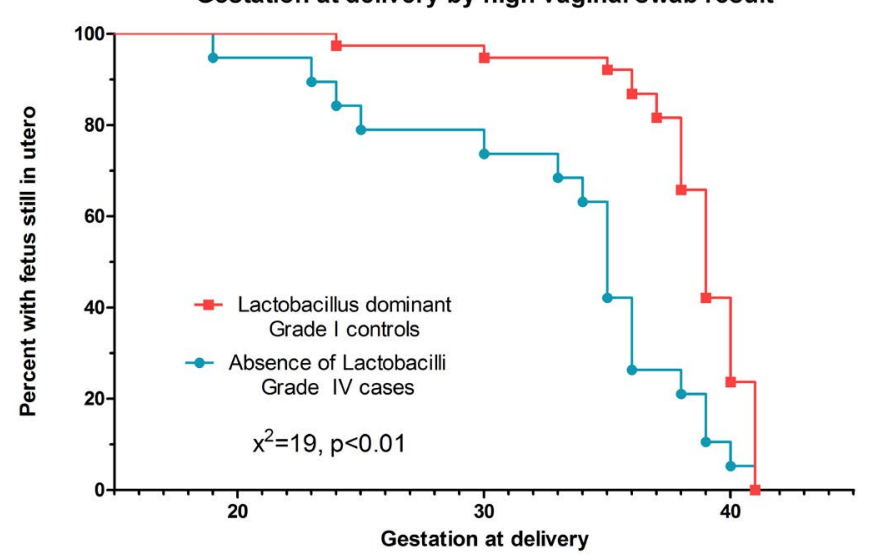

Figure 2. Survival curve showing the gestation at delivery in women with Lactobacilli, in comparison to women with an absence of Lactobacilli on Gram stain

membranes at the time of testing. In the context of this study, it is not possible to determine whether the abnormal grade IV state was present in advance of rupture of the membranes, or did it develop subsequently. This issue could only be resolved through a prospective cohort. If the abnormal state was present in advance, then this would provide an opportunity to explore the role of additional interventions (eg cervical length screening or treatment with interventions such as progesterone or lactobacillus supplementation). A second limitation is that it is not possible to directly equate the grade IV state in this study to aerobic vaginitis as more detailed microscopy was not performed to assess for polymorphonuclear cells or other markers of aerobic vaginitis [8]. Unfortunately as this was a retrospective study it was not possible to formally assess the prevalence of aerobic vaginitis using microscopy methods, but this should be incorporated in to any future projects.Molecular testing for organisms such as Mycoplasma genitalium, Chlamydia trachomatis and Ureaplasma urealyticum was also not performed as only bacterial culture swabs were taken. These organisms have been associated with preterm labour and should be included as part of any prospective cohort study [12].
In the future work should be directed at identifying women with an absence of lactobacilli in advance of membrane rupture, as it could present an opportunity to intervene. For economic reasons, consideration needs to be given to cheaper laboratory methods to diagnose this abnormal state such as Gram stains or commercial realtime PCR assays, rather than experimental methods. Given the low risk of such screening with a vaginal swab, and the potential risk of preterm birth, the use of lactobacilli supplementation with Lactobacillus reuteri and Lactobacillus rhamnosus for these women may be a therapeutic option to prevent preterm birth. As molecular methods develop for bacterial vaginosis and aerobic vaginitis diagnosis, these tests should be considered for high risk women to allow for earlier identification and treatment [13].

\section{Acknowledgements}

The authors would like to thank the staff of the Microbiology Laboratory in the Rotunda Hospital for their assistance with this work.

\section{References}

1. Romero R, Hassan SS, Gajer P, Tarca AL, Fadrosh DW, et al. (2014) The composition and stability of the vaginal microbiota of normal pregnant women is different from that of non-pregnant women. Microbiome 2: 4. [Crossref]

2. Freitas AC, Chaban B (2017) The vaginal microbiome of pregnant women is less rich and diverse, with lower prevalence of Mollicutes, compared to non-pregnant women. Sci Rep 7: 9212. [Crossref]

3. Stout MJ, Zhou Y, Wylie KM, Tarr PI, Macones GA, et al. (2017) Early pregnancy vaginal microbiome trends and preterm birth. Am J Obstet Gynecol 217: 356. [Crossref]

4. DiGiulio DB, Callahan BJ, McMurdie PJ, Costello EK, Lyell DJ, et al. (2015) Temporal and spatial variation of the human microbiota during pregnancy. Proc Natl Acad Sci U $S$ A 112: 11060-11065. [Crossref]

5. Baldwin EA, Walther-Antonio M, MacLean AM, Gohl DM, Beckman KB, et al. (2015) Persistent microbial dysbiosis in preterm premature rupture of membranes from onset until delivery. PeerJ 3: e1398. [Crossref]

6. Callahan BJ, DiGiulio DB, Goltsman DSA, Sun CL, et al. (2017) Replication and refinement of a vaginal microbial signature of preterm birth in two racially distinct cohorts of US women. Proc Natl Acad Sci U S A 114: 9966-9971. [Crossref]

7. Donders GGG, Bellen G, Grinceviciene S, Ruban K, Vieira-Baptista P (2017) Aerobic vaginitis: no longer a stranger. Res Microbiol 168: 845-858. [Crossref]

8. Han C, Wu W, Fan A, Wang Y, Zhang H, et al. (2015) Diagnostic and therapeutic advancements for aerobic vaginitis. Arch Gynecol Obstet 291: 251-257. [Crossref]

9. Krauss-Silva L, Almada-Horta A, Alves MB, Camacho KG, Moreira ME, et al. (2014) Basic vaginal $\mathrm{pH}$, bacterial vaginosis and aerobic vaginitis: prevalence in early pregnancy and risk of spontaneous preterm delivery, a prospective study in a low socioeconomic and multiethnic South American population. BMC Pregnancy Childbirth 14: 107. [Crossref]

10. Ison CA, Hay PE (2002) Validation of a simplified grading of Gram stained vaginal smears for use in genitourinary medicine clinics. Sex Transm Infect 78: 413-415. [Crossref]

11. van de Wijgert JH, Borgdorff H, Verhelst R, Crucitti T, Francis S, et al. (2014) The vaginal microbiota: what have we learned after a decade of molecular characterization? PLoS One 9: e105998. [Crossref]

12. Choi SJ, Park SD, Jang IH, Uh Y, Lee A (2012) The prevalence of vaginal microorganisms in pregnant women with preterm labor and preterm birth. Ann Lab Med 32: 194-200. [Crossref]

13. Rumyantseva TA, Bellen G, Savochkina YA, Guschin AE, Donders GG, et al. (2016) Diagnosis of aerobic vaginitis by quantitative real-time PCR. Arch Gynecol Obstet 294: 109-114. [Crossref]

Copyright: (C2018 Drew RJ. This is an open-access article distributed under the terms of the Creative Commons Attribution License, which permits unrestricted use, distribution, and reproduction in any medium, provided the original author and source are credited. 